\title{
Problemas SObRe Legitimación actiVa en LA RePARACIÓN DEL DAÑO POR FALLECIMIENTO
}

\section{Problems about active legitimation in the Repair of the Damage bY DEATH}

Mario Clemente Meoro*

Trabajo recibido el 23 de marzo de 2019 y aprobado el 4 de diciembre de 2019

\section{Resumen}

El fallecimiento de una persona, en cuanto imputable a otra, genera responsabilidad. Sin embargo, ha sido objeto de debate doctrinal y jurisprudencial quién puede, en cada caso, reclamar la reparación derivada el perjuicio causado por tal fallecimiento. Se entremezclan a este respecto cuestiones que tienen que ver con la distinta terminología y planteamiento de las normas aplicables, según que haya o no responsabilidad civil derivada de delito; y también con la posible aplicación al caso del Derecho sucesorio. A continuación, se da cuenta de las soluciones jurisprudenciales y doctrinales sobre las cuestiones planteadas.

Palabras clave: Legitimación activa, reparación del daño por fallecimiento, agraviados

\begin{abstract}
The death of a person, as imputable to another, generates responsibility. However, it has been object of doctrinal and jurisprudential debate who can, in each case, claim the compensation derived from the damage caused by such death. In this regard, questions that have to do with the different terminology and approach of the applicable norms are intermingled, according to whether there is civil liability derived from crime; and also, with the possible application to the case of inheritance law. Next, the jurisprudential and doctrinal solutions on the questions raised are reported.
\end{abstract}

Key words: Legal standing, compensation for damage by death, injured

\section{INTRODUCCIÓN}

El primer y principal sujeto legitimado para reclamar la reparación del daño es el perjudicado. Él es quien ocupa la posición activa en la relación jurídica nacida de la causación del daño resarcible. Es, por haber sido sujeto pasivo de la acción u omisión de la que el daño deriva, el acreedor de la reparación.

\footnotetext{
Mario Clemente Meoro. Doctor en Derecho y Catedrático de Derecho Civil, Universidad de Valencia, España. Correo de contacto: mario.clemente@uv.es
} 
Desde luego, puede ser perjudicada tanto una persona física como una jurídica (cfr. artículo 38 del Código Civil español, en adelante, CC); y también los entes sin personalidad (cfr. arts. 6.1. 5. y y 10 de la Ley de Enjuiciamiento Civil española; en lo sucesivo, LEC).

A continuación, se analizan, desde la perspectiva del Derecho español algunas de las cuestiones que se suscitan en relación con la legitimación activa en la reparación del daño; en concreto, las que se producen cuando la conducta dañosa determina el fallecimiento de la víctima. Hay, desde luego, muchos más problemas de legitimación activa en el Derecho español, como los que tienen que ver con la reparación por lesiones o enfermedades respecto de personas distintas de la víctima. Pero tales problemas de legitimación resultan de la regulación sobre Seguridad Social y Mutuas de Accidentes de Trabajo y Enfermedades Profesionales, lo que no sólo es complejo, sino que — supongo- poco ha de tener que ver con la realidad jurídica chilena. Es por ello que les ahorraré la exposición de estos problemas relativos a la legitimación activa por lesiones y enfermedades.

\section{Perjudicado y agraviado}

El artículo 113 del Código Penal español (en adelante, CP) establece que "la indemnización de perjuicios materiales y morales comprenderá no sólo los que se hubieren causado al agraviado, sino también los que se hubieren irrogado a sus familiares o a terceros"; con lo que se identifica al perjudicado con el agraviado por el delito, sus familiares e incluso terceros.

Sin embargo, resulta necesario distinguir al perjudicado del agraviado por el delito o víctima de este, pues cabe que éste no haya sufrido daño alguno y no tenga, por tanto, derecho a ser resarcido. Tal puede ser el caso de delitos cometidos en grado de tentativa, e incluso de delitos consumados en los que el autor no logra su propósito (v.gr., falsedad documental que no llega a utilizarse en provecho de quien la lleva a cabo y perjuicio del agraviado). Como señala la STS (Sala 2.a) 18 enero 1980 (RJ 1980, 104), "el agraviado o sujeto pasivo del delito es el ofendido que ha sufrido un daño criminal, mientras que el perjudicado es el sujeto pasivo del daño civil indemnizable o el titular del interés directa o indirectamente lesionado por el ilícito civil generador de obligaciones que, además es delito, cualidades ambas que pueden coincidir o no". Como señala, acertadamente, YZQuierdo Tolsada, M. (2015, 398), incluso cuando coincidan en la misma persona ambas cualidades, el perjudicado, por lo dicho, no es perjudicado por haber sido ofendido por el delito, sino por sufrir un daño resarcible.

En realidad, hablar de agraviado, familiares y terceros no es decir gran cosa. Es perjudicado quien sufre el daño, tanto si ha sido agraviado por un delito como si no, y con absoluta independencia de sus relaciones de cualquier índole — personales o familiares — con el agraviado.

\section{VÍCTIMA Y PERJUDICADO}

En otro orden de cosas, cabe distinguir entre víctima y perjudicado sobre la base de considerar víctima a quien padece el daño de manera directa y, en un sentido más amplio, perjudicado a todo el que padece un perjuicio a resultas del hecho dañoso, sea de forma directa (el perjudicado sería entonces la propia víctima), sea de manera mediata o como efecto indirecto del daño o mal inmediatamente irrogado a otro, por lo que se habla de víctima secundaria y de daños indirectos, reflejos, mediatos o por rebote [Gómez Calle, E. $(2014,972)$ ]. Efectivamente algunos perjudicados lo son precisamente como 
consecuencia del perjuicio que otro -la víctima- sufre, lo que plantea algunos problemas en relación con ciertos tipos de daños.

\section{El fallecimiento de la víctima}

\subsection{Planteamientos jurisprudenciales y doctrinales}

La determinación de quién resulta perjudicado por la muerte de una persona ha dado lugar a una serie de pronunciamientos jurisprudenciales contradictorios y a un intenso debate doctrinal.

Sostuvo en su momento la Sala 2. a del Tribunal Supremo que la muerte de una persona era daño que ésta sufría -la pérdida de la propia vida-, por lo que eran sus herederos los legitimados para reclamar su resarcimiento. El argumento esgrimido por la Sala era que conforme al Código Penal la acción para repetir la restitución, reparación e indemnización se transmite a los herederos del perjudicado (artículo 105.2 del anterior (P).

Sin embargo, la Sala 1. a del mismo Tribunal mantuvo desde antiguo que el derecho a la indemnización por la pérdida de la propia vida no se puede transmitir mortis causa porque no ha podido ingresar en su patrimonio antes de su muerte (cfr. artículo 659 CC).

Desde hace ya tiempo la Sala 2.a, en un primer momento con vacilaciones y luego de manera franca, ha adoptado la opinión de la Sala 1. a. Por ello, resultan acertadas las críticas realizadas a la Sentencia de la Audiencia Nacional 31 octubre 2007 (JUR 2007, 328722), dictada con ocasión del atentado terrorista del 11-M, en que no se precisaba ni la cuantía de las indemnizaciones por causa de muerte ni los beneficiarios de estas. Debieron ser dos autos de aclaración, de fecha de 2 y 22 de noviembre, los que, respectivamente, fijaran la cuantía en 900.000 euros (cantidad fija) por fallecido y declararan que "son beneficiarios de las indemnizaciones que traigan causa de víctimas fallecidas los familiares que ostenten la condición de herederos". Se quebró, con este pronunciamiento, una línea jurisprudencial consolidada, que ha atribuido el derecho a percibir una indemnización por causa de muerte de una persona no a sus herederos, sino a los "perjudicados" por el fallecimiento, tengan o no la condición de herederos. También resulta criticable que se fije una indemnización fija e idéntica para todos los beneficiarios, sin tener en cuenta sus condiciones personales [cfr. YZQuIERDo TolsadA, M. (2009, 23 y ss)].

\subsection{Daños resultantes del fallecimiento de la víctima}

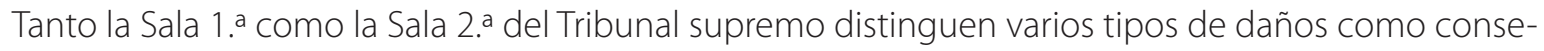
cuencia de la muerte de una persona:

1. Daños patrimoniales que constituyen cargas de la herencia y que, consecuentemente, pueden reclamar los herederos. Es el caso de los gastos de funeral y entierro (cfr. artículos 840, 902.1. a y 903 CC).

2. Daños patrimoniales sufridos por la víctima cuya muerte no se produjo de manera inmediata, como los gastos de clínica y farmacia y los ingresos dejados de obtener como consecuencia del impedimento para el trabajo de la víctima. Dado que constituyeron un daño emergente o un lucro cesante sufridos por la víctima en vida, generaron un crédito a su favor que ingresó en su patrimonio antes de su muerte y se transmite iure hereditatis.

CLEMENTE MEORO, Mario. Problemas sobre legitimación activa en la reparación del daño por fallecimiento. Revista Justicia y Derecho, Santiago, v. 2, n², 2019 
3. Daño moral consistente en la propia muerte de la víctima, que, al no ingresar en su patrimonio con anterioridad a su muerte, no puede transmitirse a sus herederos.

4. Daño moral constituido por el dolor psicofísico que la lesión mortal hace sufrir a la víctima cuando su fallecimiento no se produjo de modo inmediato. Puesto que se sufrieron en vida, el crédito para reclamar su resarcimiento puede transmitirse mortis causa.

Por eso, es incorrecto el razonamiento de la STS (Sala 3a) 16 julio 2004 (RJ 2004, 5538), en que se dilucidó la responsabilidad patrimonial de la Administración por el contagio mediante transfusión del virus de la hepatitis C a un paciente que posteriormente falleció. En ella, se condenó a indemnizar los daños morales a la madre y dos hermanos del perjudicado. Sin embargo, se contiene la siguiente afirmación: "El daño por el deterioro en la calidad de vida del enfermo desde que se le diagnosticó la enfermedad hasta su muerte (pretium doloris) no puede ser solicitada por los herederos, porque fallecida una persona se extingue su personalidad jurídica y, por tanto, no puede nacer en su favor una pretensión al resarcimiento del daño". Según esta Sentencia esta acción personalísima la hubiera podido ejercer en vida quien padeció ese daño moral e, incluso, si hubiera fallecido una vez iniciada la acción y se hubiera acreditado el daño y se hubiera dispuesto una indemnización, los beneficiarios de ella in iure proprio, "que no como herencia puesto que la indemnización no habría alcanzado a integrarse en el caudal hereditario, y, aun si así fuese, quienes tuvieran derecho a ello lo tendrían por el título de convivencia y afectividad más que por el de herederos propiamente dicho".

5. Daños patrimoniales sufridos por aquellas personas que dependían económicamente del causante o que recibían de él cierta asistencia de la que se ven privados como consecuencia de su fallecimiento. Se trata de daños que los perjudicados sufren en cabeza propia y con independencia de si son o no sucesores de la víctima.

6. Daños morales que experimentan aquellas personas vinculadas al causante por lazos de afectividad como consecuencia de su muerte.

\subsection{Legitimación para la reparación de los daños morales causados por el fallecimiento de la víctima}

Como se acaba de señalar, quien se ve privado de un ser querido sufre un perjuicio de índole moral que puede reclamar ex iure proprio, no por sucesión hereditaria. Mas desde este planteamiento el círculo de perjudicados por la muerte de una persona podría ser amplísimo: tan amplio como el número de personas que le tenían en su estima. Es por ello que los Tribunales han limitado el ámbito de los perjudicados mediante el expediente de considerar que sólo se encuentran legitimados para reclamar la reparación de tales daños morales quienes tengan mayor afinidad con el causante, con exclusión de otros.

Con arreglo a este planteamiento, la jurisprudencia ha establecido algunas reglas sobre quién puede reclamar indemnización por el daño moral que le produce la muerte de un ser querido:

a) Están legitimados en primer lugar el cónyuge y los hijos del difunto, quienes pueden concurrir en la pretensión resarcitoria.

En cuanto al cónyuge viudo, resulta discutible que también tenga derecho a indemnización el que estuviera separado del difunto.

Se alega al respecto la STS (Sala 2.a) 5 julio 1999 (RJ 1999, 5818), afirmándose que en ella se admitió la legitimación activa de la viuda separada legalmente antes del óbito; pero hay que tener en cuenta que en la sentencia recurrida no se consideró que la viuda estuviera separada legalmente: había procedi- 
miento de separación, pero no se llegó a dictar sentencia antes del fallecimiento; y que la sentencia recurrida atribuyó la indemnización que según la Tabla I del Sistema de Valoración de Daños Personales de la Ley de Responsabilidad Civil y Seguro en la Circulación de Vehículos de Motor corresponde a la viuda, no sólo a ésta sino también a la pareja de hecho del difunto (seis millones de pesetas a cada una de ellas).

En sentido distinto cabe citar la STS (Sala 2.a) 19 mayo 1969 (RJ 1969, 2894), que desestimó la pretensión de la viuda sobre la base de estar separada de hecho del marido más de veinte años y haber obtenido sentencia del Tribunal Eclesiástico doce años antes del fallecimiento por la que obtuvo la separación por adulterio del esposo; la STS (Sala 2.a) 12 noviembre 1981 (RJ 1981, 4317), que desestimó la pretensión indemnizatoria de la viuda separada del difunto más de seis años con base en haber cesado la convivencia y no existir ya affectio maritalis de los cuales de los cuales cupiera conjeturar o inferir que la mujer sufrió daños morales que merezcan digna reparación; la SAP León 26 marzo 1996 (AC 1996, 554), que deniega indemnización a la viuda sobre la base de no haber entre los cónyuges affectio maritalis ni convivencia, estando separados de hecho al menos desde tres meses antes del accidente y habiendo sido interpuesta demanda de separación por el cónyuge que luego falleció; y la SAP Salamanca 26 junio 2000 (AC 2000, 1448), que estimó la pretensión de la pareja de hecho de la fallecida y desestimó la de su viudo, del que estaba legalmente separado.

A mi juicio, resulta más correcta esta segunda doctrina jurisprudencial. Si ya no hay convivencia ni afecto entre los cónyuges, no cabe presumir el daño moral de uno de ellos por el fallecimiento del otro. Sólo probando que tal tipo de perjuicio se ha producido (porque, por ejemplo, la separación de hecho es reciente y fue unilateralmente impuesta por el cónyuge fallecido) cabría conceder indemnización al cónyuge viudo separado; desde luego cuando lo está legalmente, pero también si lo está meramente de hecho.

Los hijos tienen derecho a ser indemnizados por la muerte de su progenitor también si son mayores de edad y no convivían ni dependían económicamente de él, sin perjuicio de que tales circunstancias resulten relevantes a la hora de fijar la cuantía de la indemnización. Mas carecen de legitimación activa para reclamar daños morales los hijos que habían roto todos los vínculos afectivos con el difundo, incluso por culpa de éste.

Si los hijos del fallecido están bajo la patria potestad del otro progenitor, viudo del fallecido, éste puede reclamar tanto en nombre propio como en representación de aquéllos.

b) En relación con la cuestión de la asimilación de la pareja de hecho al cónyuge, a los efectos de reconocerle legitimación para reclamar indemnización por causa de fallecimiento del otro miembro de la unión, habrá que estar, como venimos sosteniendo, a su condición de "perjudicado", atendiendo a la convivencia y lazos de afectividad entablados con el fallecido. Por ello, el reclamante deberá acreditar que, efectivamente, formaban una pareja de hecho unida de forma permanente por relación de afectividad análoga a la conyugal, lo que, según alguna jurisprudencia, se consigue ofreciendo prueba de coexistencia diaria y estable, compartiendo domicilio, con permanencia temporal consolidada y practicada de forma externa y pública, además de una comunidad de vida, intereses y fines en el núcleo del mismo hogar.

Al respecto, cabe tener en cuenta la existencia de diversas leyes autonómicas sobre uniones de hecho que exigen, para apreciar una "unión de hecho" a la que será aplicable sus disposiciones, determinados requisitos que, no obstante, difieren en algunas de ellas. A nuestro juicio, los tribunales sólo deberán atender a la condición de "perjudicado", esto es, a la constatación de un efectivo daño moral, por el sufrimiento padecido por el miembro de la pareja de hecho supérstite, dado el vínculo de afectividad que existía entre ellos. 
c) En ausencia de cónyuge e hijos, los padres del fallecido pueden reclamar indemnización por daño moral ex iure proprio; incluso se ha admitido su legitimación en concurrencia con el cónyuge del fallecido o con su pareja de hecho; y también con los hijos de la víctima. Es más, el Tribunal Supremo ha llegado a considerar legitimados para reclamar daños morales a los padres por la muerte de un hijo que se encontraba en el momento de su fallecimiento bajo la tutela de una entidad pública, incluso por causa del abandono de aquéllos.

d) En ausencia de hijos, cónyuge y padres, se ha admitido la legitimación de los nietos; e incluso en concurrencia de los nietos con los hijos sobre la base de considerar que representan a su padre premuerto, con evidente confusión entre herederos y perjudicados.

Más allá, la STS (Sala 1.a) 14 junio 2007 (RJ 2007, 3518) concede indemnización a un nieto del fallecido en accidente en un aserradero en concurrencia con la viuda y tres hijos, sobre la base de haber convivido el nieto con su abuelo y estar a su cargo desde los tres años y ser estudiante sin ingresos propios, frente a la mayoría de edad e independencia económica de los hijos no convivientes.

e) En esas mismas circunstancias, esto es, en ausencia de hijos, cónyuge y padres, también se ha admitido la legitimación de los abuelos en concurrencia con los hermanos de la víctima.

f) También se ha considerado legitimados a los hermanos que no concurrían con familiares más próximos; e incluso concurriendo con los padres del fallecido, con los abuelos, con hijos y con compañera sentimental; y esto, aunque tales hermanos no convivieran ni dependieran económicamente del fallecido.

g) En la medida en que convivían con la víctima y no había familiares más próximos se ha considerado activamente legitimados a los tíos.

h) Sin embargo, se ha negado tal legitimación a los sobrinos que concurrían con el cónyuge viudo o con el padre del uno de los fallecidos.

i) Más allá del círculo de los familiares se ha admitido la legitimación activa de algunas personas especialmente allegadas a la víctima. Es el caso de la persona que convivía con el fallecido como si fuera su hijo, aunque no hubiese sido adoptado; de los hijastros de la víctima, hijos del primer matrimonio de su marido, igualmente fallecido en el accidente, que convivían con ellos y colaboraban en la explotación familiar, quienes fueron indemnizados en concurrencia con el padre de una de las víctimas; de quien había cuidado de la víctima y convivido con ella durante años; de la novia del fallecido, en concurrencia con sus padres; de la pareja de hecho estable; e incluso del "padre de hecho", esto es, al compañero sentimental de la madre cuya hija falleció, en concurrencia con ésta.

Podría también admitirse legitimación activa a los guardadores que tienen en acogimiento a menores desamparados y, por la misma razón, al menor que convivía en régimen de acogimiento permanente familiar con la víctima.

Del sistema que resulta de la jurisprudencia reseñada se ha dicho que es de una artificiosidad flagrante y sirve únicamente para alterar el orden sucesorio en favor de soluciones más realistas y adaptadas al caso; que si el perjuicio por la muerte no lo sufre el difunto, habría de repararse el daño moral que sufren los diversos parientes y allegados de la víctima frente a todos y cada uno de ellos, pues no hay razón para dividirlos en clases, como si los padres no llorasen la muerte de sus hijos aunque éste se haya casado y tenga descendencia [LACRUz $(1985,522)]$; y que la postura jurisprudencial "es criticable; por un lado, porque ni la indemnización es tasada, ni hay por qué valorar igual todos los daños morales, ni valorar mucho el de los parientes lejanos; de otra parte, tampoco hay razón para dejar sin indemnización a aquellos que efectivamente sufren un daño moral, por el hecho de que el fallecido dejara algún pariente más próximo" [Gómez Calle $(2014,976)]$. 
En efecto, parece evidente que la jurisprudencia quiso huir de la aplicación de las reglas de la sucesión intestada en la medida en que condenaban al cónyuge viudo a no ser indemnizado más que si el difunto no dejaba descendientes, ascendientes, hermanos ni sobrinos; mas no ha aplicado hasta sus últimas consecuencias el principio del que parte, esto es, que son los parientes y allegados del difunto, todos ellos, en mayor o menor medida, los que sufren su pérdida. La jurisprudencia, temerosa acaso de extender en exceso la legitimación para reclamar indemnización por daño moral, ha optado por limitar el círculo de afectados y anteponer unos a otros; aunque no siempre, pues en ocasiones permite que concurran unos parientes o allegados con otros.

Puede afirmarse, no obstante, que el eje del sistema está en una doble presunción: de existencia de perjuicio cuando es próximo el parentesco y de su inexistencia cuando no hay parentesco, cuando es lejano o cuando existen parientes más próximos; pero admitiendo prueba en contrario en ambos casos. El cónyuge e hijos de la víctima no han de probar más que su condición de tales, pues se presume su dolor, pero cabrá probar que no sufrieron daño moral alguno por no mediar relación afectiva de ningún tipo entre el difunto y sus familiares más próximos. A la inversa, la falta de parentesco, su lejanía o la existencia de parientes más próximos no serán óbice si se prueba el perjuicio, normalmente derivado de situaciones convivenciales y vínculos de afectividad.

\section{Bibliografía Citada}

Gómez Calle, Esther (2014): "Los sujetos de la responsabilidad civil. La responsabilidad por hecho ajeno", en L. F. Reglero Campos y J. M. Busto Lago (Coords.), Tratado de Responsabilidad Civil (Cizur Menor, Aranzadi, 5 a ed.).

Lacruz Berdejo, J. L. (1985): Elementos de Derecho Civil, tomo II, Derecho de obligaciones, vol. 10, Parte General.

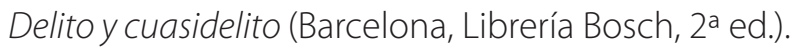

Llamas Pombo, E. (2008): "Responsabilidad civil por los atentados del 11-M", Revista Práctica Derecho de Daños, Revista de Responsabilidad Civil y Seguros, núm. 56, pp. 3-4.

Yzquierdo Tolsada, Mariano (2009): "A cuestas con los herederos, los familiares y los perjudicados", Revista de Responsabilidad Civily Seguro, núm. 31, pp. 23 y ss. Disponible en http://www.asociacionabogadosrcs.org YZQuierdo TolsadA, Mariano (2015): Responsabilidad civil extracontractual. Parte general (Madrid, Dykinson).

\section{NORMAS CITADAS}

Decreto 3096/1973, de 14 de septiembre, por el que se publica el Código Penal, texto refundido conforme a la Ley 44/1971, de 15 de noviembre.

Ley 1/2000, de 7 de enero (Ley de Enjuiciamiento Civil), actualizada a 19.03.2019.

Ley Orgánica 10/1995, de 23 de noviembre (Código Penal español), actualizado a 04.03.2019.

Real Decreto de 24 de julio de 1889 (Código Civil español), actualizado a 19.03.2019. 


\section{JURISPRUDENCIA CITADA ${ }^{1}$}

STS (Sala 1a) 14 junio 2007 (RJ 2007, 3518)

STS (Sala 2a) 19 mayo 1969 (RJ 1969, 2894)

STS (Sala 2a) 18 enero 1980 (RJ 1980, 104)

STS (Sala 2a) 12 noviembre 1981 (RJ 1981, 4317)

STS (Sala 2a) 5 julio 1999 (RJ 1999, 5818)

STS (Sala 3a) 16 julio 2004 (RJ 2004, 5538)

SAN 31 octubre 2007 (JUR 2007, 328722)

SAP León 26 marzo 1996 (AC 1996, 554)

SAP Salamanca 26 junio 2000 (AC 2000, 1448)

1 STS: Sentencia del Tribunal Supremo; SAN: Sentencia de la Audiencia Nacional; Sentencia de la Audiencia Provincial; RJ: Repertorio de Jurisprudencia (Aranzadi); AC: Aranzadi Civil; JUR: Sentencias y Autos de la Audiencia Nacional, Tribunales Superiores de Justicia, Audiencias Provinciales y Juzgados (Aranzadi).

CLEMENTE MEORO, Mario. Problemas sobre legitimación activa en la reparación del daño por fallecimiento. Revista Justicia y Derecho, Santiago, v. 2, n², 2019 